NBER WORKING PAPER SERIES

\title{
THE IMPACT OF THE COVID-19 VACCINE DISTRIBUTION ON MENTAL HEALTH OUTCOMES
}

\author{
Virat Agrawal \\ Jonathan H. Cantor \\ Neeraj Sood \\ Christopher M. Whaley \\ Working Paper 29593 \\ http://www.nber.org/papers/w29593 \\ NATIONAL BUREAU OF ECONOMIC RESEARCH \\ 1050 Massachusetts Avenue \\ Cambridge, MA 02138 \\ December 2021
}

Support was provided by the National Institute on Aging (Grant No. 1K01AG061274 to Christopher Whaley). The funding source had no role in the design and conduct of the study; collection, management, analysis, and interpretation of the data; and preparation, review, or approval of the manuscript. The views expressed herein are those of the authors and do not necessarily reflect the views of the National Bureau of Economic Research.

NBER working papers are circulated for discussion and comment purposes. They have not been peer-reviewed or been subject to the review by the NBER Board of Directors that accompanies official NBER publications.

(C) 2021 by Virat Agrawal, Jonathan H. Cantor, Neeraj Sood, and Christopher M. Whaley. All rights reserved. Short sections of text, not to exceed two paragraphs, may be quoted without explicit permission provided that full credit, including $\odot$ notice, is given to the source. 
The Impact of the COVID-19 Vaccine Distribution on Mental Health Outcomes

Virat Agrawal, Jonathan H. Cantor, Neeraj Sood, and Christopher M. Whaley

NBER Working Paper No. 29593

December 2021

JEL No. I1,I12

\begin{abstract}
The COVID-19 pandemic has led to a "second pandemic" of anxiety and depression. While vaccines are primarily aimed at reducing COVID-19 transmission and mortality risks, they may have important secondary benefits. We use data from U.S. Census Bureau's Household Pulse Survey merged to state-level COVID-19 vaccination eligibility data to estimate the secondary benefits of COVID-19 vaccination on mental health outcomes. To address endogenous COVID-19 vaccination, we leverage state-level variation in the timing of when age groups are eligible for vaccination. We estimate that COVID-19 vaccination reduces anxiety and depression symptoms by nearly $30 \%$. Nearly all the benefits are private benefits, and we find little evidence of spillover effects, that is, increases in community vaccination rates are not associated with improved anxiety or depression symptoms among the unvaccinated. We find that COVID-19 vaccination is associated with larger reductions in anxiety or depression symptoms among individuals with lower education levels, who rent their housing, who are not able to telework, and who have children in their household. The economic benefit of reductions in anxiety and depression are approximately $\$ 350$ billion. Our results highlight an important, but understudied, secondary benefit of COVID-19 vaccinations.

Virat Agrawal

USC Sol Price School of Public Policy

Los Angeles, CA

United States

viratagr@usc.edu

Jonathan H. Cantor

RAND Corporation

1776 Main Street

Santa Monica, CA 90401

jcantor@rand.org

Neeraj Sood

Schaeffer Center for Health Policy and Economics

Sol Price School of Public Policy

University of Southern California

University Park Campus

Los Angeles CA 90089

and NBER

nsood@healthpolicy.usc.edu

Christopher M. Whaley

RAND Corporation

1776 Main Street

Santa Monica, CA 90401

cwhaley@rand.org
\end{abstract}




\section{INTRODUCTION}

Vaccines save millions of lives by limiting the spread of disease to the unvaccinated and by preventing disease ( $\mathrm{Li}$ et al. 2021). However, prevention of disease is not the only benefit of vaccines. Vaccines can also reduce stress and anxiety caused by the threat of infection, and particularly relevant during the COVID-19 pandemic, also reduce the adverse consequences of risk mitigation strategies such as social isolation. In part due to uncertainty about the future of the course of the pandemic, concerns about COVID-19 infection, social isolation while under shelter-in-place policies, and economic uncertainty or job loss, many experts predicted a "second pandemic" of mental and behavioral health problems due to the pandemic (Breslau et al. 2021; Raviv et al. 2021; Ettman et al. 2020). By December 2020, over 40\% of U.S. adults reported symptoms of anxiety or depression (Vahratian et al. 2021). However, the introduction of vaccines in December offered hope and optimism. In this paper, we paper examine the complex effects of COVID-19 vaccines on mental health.

Vaccines may improve mental health through both private and external pathways (Koltai et al. 2021; Blanchflower and Bryson 2021). Vaccinated individuals face dramatically lower risks of COVID-19 infection and lower severity of COVID-19 illness (Polack et al. 2020; Baden et al. 2021; Sadoff et al. 2021; Thomas et al. 2021; Bajema et al. 2021). This direct impact of vaccines reduces uncertainty about the future - what will happen if I get infected - which in turn might reduce a vaccinated person's anxiety or depression associated with fears of infection risk (PerezArce et al. 2021). Vaccinations can also have spillover effects. In particular, increased vaccination by others within a community also reduces private risks of infection, which can also reduce private concerns of COVID-19 infection. Increased community vaccination also reduces social distancing and willingness to stay at home (Andersson et al. 2021), which can reduce the 
mental health effects of social isolation. Broader vaccination can enable large-scale social gatherings (e.g., restaurants, return to work, in-person school), more than when just isolated social networks are vaccinated. Through this pathway, the increase in community vaccination rate can have spillover effects on mental health of others in the community including the unvaccinated.

There are external benefits to having as many individuals vaccinated as possible. As a result, many economic policies focus on increasing vaccination rates (Carpenter and Lawler 2019). During the COVID-19 pandemic, these policies range from free Krispy Kreme donuts, to staterun lotteries (Walkey, Law, and Bosch 2021; Brehm, Brehm, and Saavedra 2021; Barber and West 2021), to workplace requirements that require vaccination (Klompas, Pearson, and Morris 2021). These policies are aimed to address the primary external benefit of COVID-19 vaccination's impact on COVID-19 transmission. However, the potential spillover effects of such vaccine campaigns on mental health have not been studied.

The potential mental health benefits of COVID-19 vaccines might be an important part of the total benefits of COVID-19 vaccines. Prior to the COVID-19 pandemic, mental health disorders accounted for over $\$ 200$ billion in annual medical spending in the United States (Roehrig 2016). Cutler and Summers (2020) estimate that the total cost of the COVID-19 pandemic may reach as high as $\$ 16$ trillion. Given the striking increase in anxiety and depression during the pandemic, Cutler and Summers give particular attention to the mental health costs of the pandemic and estimate that the costs of depression and anxiety approximates $\$ 20,000$ per-person per-year. Assuming that the mental health symptoms last for only one year, they conclude that valuation of mental health costs due to the pandemic can be as high as $\$ 1.6$ trillion. If vaccines do have an 
impact on mental health conditions, then the expected cost of the pandemic could be greatly reduced.

In this paper, we examine the mental health effects of COVID-19 vaccines using a nationwide survey of households conducted by the United States Census Bureau. Starting in April 2020 and continuing throughout the pandemic, the Household Pulse Survey (HPS) has surveyed approximately 2.5 million people from April, 2020 to May, 2021 in the United States on mental health symptoms. Throughout the pandemic, separate cross-sectional waves of the survey are conducted every one-to-two weeks. In addition to a rich set of demographic controls, a unique feature of this data is that it also contains respondent-level information on COVID-19 vaccinations. The data have been used previously to track mental distress during the pandemic (Park 2021; Park and Kim 2021; Cai et al. 2021). They have also been used to examine the association between receiving the COVID-19 vaccine and self-reported anxiety and depression (Chen, Aruldass, and Cardinal 2022). However, there are currently no studies that have used the HPS to causally identify the effect of COVID-19 vaccine eligibility on self-reported anxiety and depression.

We merge the HPS with state-level data on COVID-19 vaccine eligibility to identify the effects of COVID-19 vaccination on mental health outcomes. We leverage state and age timing when individuals are eligible to receive COVID-19 vaccines as an instrument for receiving a vaccine. To address the potential that increased vaccine rates create spillovers that improve mental health for unvaccinated populations, we also estimate specifications that control for the share of vaccinated people at the state level and include fixed effects for state-survey wave interactions. 
Using these sources of variation, we find that receiving a COVID-19 vaccine leads to large improvements in mental health. In our OLS regressions, we find that COVID-19 vaccines lead to a 3.1 and 3.4 percentage point reduction in anxiety and depression symptoms, respectively, which, relative to mean 2020 rates, translate to relative reductions of $9.5 \%$ and $12.9 \%$, respectively. When instrumenting for COVID-19 vaccination using variation in eligibility rules, we find much larger, 9.4 and 7.2 percentage point reductions for anxiety and depression symptoms, respectively. These instrumented reductions translate to an approximately $28 \%$ reduction in symptoms. Importantly, we find little evidence of external benefits of COVID-19 vaccination on mental health. Instead, nearly all of the reductions in anxiety/depression symptoms are private benefits. We do not find that increases in community vaccination rates lead to reductions in mental health symptoms or changes in symptoms among individuals who have not been vaccinated.

The impacts of the COVID-19 pandemic have not been equally distributed, with lowerincome and socioeconomic status populations experiencing higher rates of infection and mortality (Siddique et al. 2020; Whitaker et al. 2021; Anand et al. 2021). The economic consequences of the pandemic have been worse among these populations as well (Baker 2020; Cajner et al. 2020; Montenovo et al. 2020). In particular, measures of hardship (defined as food insufficiency, employment income loss, housing instability, health problem, and school closure) were higher for blacks and Hispanics than whites during the COVID-19 pandemic (Park 2021). Correspondingly, we find substantial heterogeneity in the secondary mental health benefits of vaccines. For example, among households able to telework doing the pandemic, we do not find improvements in mental health symptoms, but find a 9.8 and 5.8 percentage point reduction in anxiety and depression symptoms among workers unable to telework during the pandemic. We 
also find larger mental health benefits among people employed in the private sector, households that rent instead of own, households with children, and individuals with lower incomes and education. These results suggest that vaccines can reduce the total disproportionate effect the pandemic has on the mental health of lower socioeconomic populations.

Our results highlight an important secondary benefit of COVID-19 vaccines. The improvements in mental health status are not accounted for in current assessments of COVID-19 benefits. These secondary benefits are not commonly accounted for in most evaluations of the effectiveness of medical treatments, including vaccines. However, these secondary effects can provide large benefits to society and should be included when assessing the COVID-19 vaccine rollout. Preliminary estimates quantify that the initial rollout of the COVID-19 vaccine was associated with 140,000 deaths averted and a total $\$ 625$ billion and $\$ 1.4$ trillion in lives saved (Gupta et al. 2021). Our results show that the benefits will likely be significantly higher when including improvements in mental health.

\section{DATA}

\subsection{Household Pulse Survey}

To measure mental health outcomes during the COVID-19 pandemic we use data from the Household Pulse Survey (HPS), conducted in multiple waves by the U.S. Census Bureau in partnership with thirteen other federal agencies, starting April 23, 2020. The HPS collects crosssectional data in each wave of the survey during the pandemic to understand how the pandemic has affected the lives and livelihoods of American households. The data include social and economic impacts on adults who are ages 18 and older. The survey questions on mental health focus on self-reported symptoms of anxiety, worry, loss of interest, and feeling down. 
Specifically, questions that are a modified version of the two-item Patient Health Questionnaire (PHQ-2) and the two-item Generalized Anxiety Disorder (GAD-2) (Centers for Disease Control and Prevention 2021). Both the two question PHQ-2 (Kroenke, Spitzer, and Williams 2003), and the GAD-2 are validated measures (Plummer et al. 2016). Responses are scaled from 1 (Not at all) to 4 (Nearly every day). We follow the Center for Disease Control and Prevention (CDC) scoring and estimation guidelines and rescale the indices for the questions related to mental health. ${ }^{1}$ These measures are fully described in Appendix 1.

Following the CDC aggregation standards, the two self-reported responses on anxiety and worry are added together to create the variable "Generalized Anxiety Disorder," and the remaining two responses on having little interest and feeling down are added together to create the variable "Major Depressive Disorder." For both Generalized Anxiety Disorder and Major Depressive Disorder, a sum equal to three or greater is associated with anxiety disorder and depressive disorder, respectively (see Appendix - Household Pulse Survey for detail). It is important to note that a diagnostic evaluation for anxiety disorder or depressive disorder was not conducted (Czeisler 2020). The measures are based on self-reported survey responses.

This study uses data from Wave 1 (April 23, 2020 to May 5, 2020) to Wave 30 (May 12, 2021 to May 24, 2021). The 30 waves combined contain 2,543,614 observations. The final dataset includes a total of 2,035,847 observations after dropping the observations that had variables of interest with response: -99 (Question seen but category not selected) or -88 (Missing / Did not report). For each survey respondent, the HPS also collects data on age, gender, race/ethnicity, education, marital status, and income, which we use as covariates. The construction of these covariates is described in the Appendix.

\footnotetext{
${ }^{1}$ We rescale the 1 to 4 values to 1 to 3, where 0 is Not at all, 1 is Several days over the last 7 days, 2 is More than half the days over the last 7 days, and 3 is Nearly every day over the last 7 days.
} 


\subsection{Vaccine Data}

Beginning in survey wave 22 (survey period January 6, 2021 to January 18, 2021), the HPS survey added a question on whether the respondent has received a COVID-19 vaccine. We use responses to this survey question to record self-reported vaccination status as 1 for "Yes" and 0 otherwise.

\subsection{Vaccine Eligibility Data}

We use vaccine eligibility data from the COVID-19 U.S. State Policy Database maintained by Boston University (Raifman et al. 2020). The data contain detailed information on state-level policies enacted during the COVID-19 pandemic and have been used to evaluate the effect of state-level policies on COVID-19 transmission and physical distancing (Feyman et al. 2020; Yang et al. 2021; Jay et al. 2020). We use the age-based vaccine eligibility dates to determine whether an individual is eligible for a vaccine within a state. We leverage the state and age variation in the timing of vaccine eligibility as an instrument for vaccine receipt. ${ }^{2}$

\subsection{Characteristics of Study Population}

The total sample size for the study is $2,035,847$ adults, out of which 247,406 adults are vaccinated and 1,788,441 adults are unvaccinated. The difference in the sample size of the vaccinated and unvaccinated populations is due to the timeline of the survey. The survey started in April, 2020, whereas, vaccination started in December, 2020, and thus, the dataset has more observations on unvaccinated adults.

2 We used eligibility based on the age group and state rollout policy to determine whether a respondent is eligible in a given survey wave or not. If a respondent turned eligible between the middle date of $n-1^{\text {th }}$ survey wave and the middle date of $\mathrm{n}^{\text {th }}$ survey wave, then that individual is considered eligible in the $\mathrm{nth}$ wave of the survey for our analysis. 
Table 1 presents summary statistics of dependent variables Anxiety Disorder and Depressive Disorder, and covariates used in this study for the total sample, and separately for the vaccinated, and unvaccinated subpopulations. The mean value and the standard deviation of all covariates in the three groups are similar. However, the mean value of the dependent variables varies between the vaccinated and unvaccinated pool because, as expected, the prevalence of anxiety and depressive disorder is higher among the unvaccinated compared to the vaccinated.

We present trends in anxiety, depression, and vaccination rates for the study sample from the U.S. HPS for the sample period in Figure 1. Rates of anxiety and depression steadily increased between the week of May 14, 2020 to July 16, 2020. Anxiety and depression rates then declined precipitously until the week of August 19, 2020, before rising again through the end of the year. The self-reported vaccination rates started in the week of December 9, 2020 and have risen sharply though the end of the sample period. It is important to note that the rates of anxiety and depression also decline after the introduction of the COVID-19 vaccine.

\section{ESTIMATION APPROACH}

This study analyzes the impact of COVID-19 vaccinations on changes in self-reported anxiety and depression symptoms. We start by descriptively estimating the association between COVID-19 vaccinations and prevalence of symptoms for anxiety and depression. In particular, we plot the share of respondents with self-reported anxiety and depression and the share of respondents with at least one COVID-19 dose by survey wave. To measure association between COVID-19 vaccination and mental health, we estimate OLS regressions with each mental health outcome as the dependent variable and COVID-19 vaccination as the key independent variable. We estimate separate regressions for each outcome-COVID-19 vaccination receipt, controlling 
for individual characteristics (age, race, education level, marital status, income, and gender). We also add fixed effects for state and survey wave.

Of course, receipt of COVID-19 is endogenous, and unobserved factors that influence the decision to receive a vaccine could be correlated with unobserved mental and behavioral health confounders. To address this concern, we instrument for vaccine receipt using variation in statelevel eligibility policies to estimate the effect of COVID-19 vaccination on anxiety and depression symptoms:

$$
\begin{gathered}
\text { vaccine }_{i s t}=\alpha_{0}+\alpha_{1} Z_{i s t}+\beta_{1} X_{i t}+\gamma_{s}+\tau_{t}+u_{i s t} \\
M H_{i s t}=\beta_{0}+\beta_{1} \text { vaccin }_{i s t}+\beta_{1} X_{i t}+\gamma_{s}+\tau_{t}+\varepsilon_{i s t}
\end{gathered}
$$

In this model, $M H_{i s t}$ represents our two outcomes of interest-self-reported anxiety and depression symptoms, $X_{i t}$ contains the patient controls described above. We also include state $\left(\gamma_{s}\right)$ and survey wave $\left(\tau_{t}\right)$ fixed effects. $Z_{i s t}$ represents the state-level eligibility policies that are used to predict self-reported vaccination status. We cluster all standard errors at the state level and estimate using two-stage least squares. All regressions are weighted using the HPS survey weights to make the survey nationally representative.

The validity of this approach relies on the standard instrumental variable assumptions. Our first stage of the effect of vaccine eligibility indicates that becoming eligible for vaccination leads to a 26.1 percentage point increase in receiving a COVID-19 vaccine (Table 2). We test for whether the state eligibility policies are a weak instrument using the Kleibergen-Paap F-statistic (Kleibergen and Paap 2006). We find the range for our estimate is from 339 to 318, which are well above conventional thresholds (Stock and Yogo 2005; Lee et al. 2020).

The second, and more challenging, assumption is that variations in vaccine eligibility do not impact mental health symptoms outside of receiving a COVID-19 vaccine. This assumption 
faces challenges in our setting. Increased vaccination rates within a community may lead to reductions in mental health symptoms if there are external benefits of vaccination on mental health. For example, non-vaccinated individuals may be more willing to see family and friends or return to work if others in their community have been vaccinated. Similarly, the distribution of the COVID-19 vaccine may have encouraged mental health providers to accept in-person appointments. At the beginning of the COVID-19 pandemic, the CDC recommended deferring in-person care and using telehealth (Centers for Disease Control and Prevention 2020). Once the COVID-19 vaccine was distributed, these guidelines were revised. This external benefit of vaccines via these two pathways could lead to reductions in a person's mental health symptoms that would violate the exclusion restriction assumption of our instrument.

As a solution, we use two approaches. First, we control for the share of vaccinated individuals in each state during each survey wave in equations (1) and (2). These controls account for the aggregate external and social benefits of vaccination. Second, we nonparametrically control for unobserved shocks to each state (e.g., the implementation of social distancing policies, changes in COVID-19 exposure, or economic conditions) by including fixed effects that interact the state and survey wave fixed effects in equations (1) and (2). In this specification, identification comes from comparing vaccinated and unvaccinated adults within the same state and time period, with exogenous variation in vaccination coming from differences in age-based eligibility for vaccination. For example, within the same state and same time period 64-year-olds might be less likely to be vaccinated compared to 65 -year-olds if 65 years were eligible for vaccines in that period and 64-year-olds became eligible for vaccines at a later date. This specification isolates within-state and time differences in outcomes between eligible and non-eligible populations. 
We compare the results of these specifications with our main specification. Finding large differences between our main model, which does not account for external benefits of vaccination on mental health, and the two models that do, would suggest the presence of vaccine externalities that would violate the exclusion restriction and threaten the validity of our instrument.

\section{RESULTS}

\subsection{Effect of COVID-19 Vaccination on Mental Health Symptoms}

Table 3 presents results showing the estimated effect of COVID-19 vaccination on mental health outcomes. Panel A presents OLS regression results for the probability of reporting anxiety symptoms (odd-numbered columns) or depression symptoms (even-numbered) columns. Columns 1 and 2 include just the individual-level covariates and fixed effects for state and survey wave period. To control for vaccine externalities, columns 3 and 4 add the share of vaccinated adults, and columns 5 and 6 interact the state and survey wave fixed effects. Across all specifications, we find that receiving a COVID-19 vaccine is associated with 3.1 and 3.4 percentage point reductions in anxiety and depression symptoms, respectively. These reductions translate to relative reductions of approximately $9.5 \%$ and $12.9 \%$.

In Panel B, we instrument for COVID-19 vaccine receipt using variation in the timing of state- and age-specific eligibility rules for COVID-19 vaccination. We use the same approach to control for vaccine externalities and find minimal impact of adding the controls for the share vaccinated and the state-survey wave fixed effect interactions. We estimate that receiving a COVID-19 vaccination leads to a reduction in anxiety symptoms that ranges from 9.4 to 9.2 percentage points, which translates to a relative reduction that ranges from $28.7 \%$ to $27.8 \%$. For 
depression symptoms, we estimate a 7.2 to 7.1 percentage point reduction, which translates to a relative reduction of $27.5 \%$ to $27.1 \%$.

In both the OLS and 2SLS results, the controls for vaccine externalities have little impact on the association between vaccine receipt and self-reported anxiety/depression symptoms. In both models, the state vaccination share coefficients are small in magnitude and not statistically significant. The lack of change in the regression coefficients suggests that, at least when measured at the state level, there are few external benefits of COVID-19 vaccines on mental health. Instead, nearly all of the benefits are private benefits to mental health. It is possible that the external benefits could be at a different level than the state-level. For example, individuals may not receive mental health benefits when people throughout their state become vaccinated but may have mental health benefits if friends and family receive COVID-19 vaccinations.

\subsection{Heterogeneity in COVID-19 Benefits}

The impacts of the COVID-19 pandemic have not been borne equally. The health impacts of the pandemic, primarily measured through excess deaths and COVID-19 infections, have disproportionately impacted low-income and racial minority communities (Polyakova et al. 2021; Jay et al. 2020; Azar et al. 2020; Kim, Marrast, and Conigliaro 2020; Park 2021). These disparities extend outside of direct health impacts. School closures were more likely to impact lower-income and racial minority communities (Bravata et al. 2021; Oster et al. 2021). A substantial share of work shifted to remote and telework environments, with "white collar" and professional workers more likely to be able to work remotely (Brynjolfsson et al. 2020). Finally, many families with children, and particularly women, experienced labor market disruptions due to schooling and childcare responsibilities (Petts, Carlson, and Pepin 2021; Lim and Zabek 2021). 
These varying impacts of the COVID-19 pandemic can create differential changes to mental health outcomes following vaccination. Individuals for whom risks of infection, family responsibilities, or work location may have larger improvements in mental health following vaccination than those with fewer burdens. These additional benefits could also lead to increases in vaccination rates, and so to explore these differential impacts, we use the same identification approach to compare changes in anxiety and depression symptoms following vaccination among different subpopulations. We leverage the breadth of the HPS data, and examine differences based on individual race, income, education attainment, housing status (e.g., rent vs. own), whether or not there are children in the household, the ability to telework during the pandemic, and industry.

Figure 2 presents coefficients from the OLS and IV specifications that include state-by-week fixed effect interaction controls. Panel A presents OLS results, which do not account for endogeneity in vaccine receipt. If unobserved reasons for COVID-19 vaccination vary across sub-populations - for example, due to access barriers - then the OLS results may be particularly biased. In Panel B, our IV results show a meaningful difference by socioeconomic status and work status during the pandemic. We find statistically significant reductions in self-reported anxiety symptoms among whites and blacks, but non-statistically significant reductions among Asians and Hispanics. We only find reductions in depression symptoms among white HPS respondents. For education, we find a 9.1 percentage point reduction in anxiety for individuals with a high school education or less and 12.8 and 10.2 percentage point reductions in anxiety and depression symptoms among individuals with some college. For individuals with a college degree or more, we find an approximately 6 percentage point reduction in both anxiety and depression symptoms. We also find an approximately 5 percentage point reduction in 
anxiety/depression symptoms among households that own their housing, compared to 20.1 and 18.6 percentage point reductions in anxiety and depression symptoms among households that rent. Among households with children in the household, we find a 17.3 percentage point reduction in anxiety symptoms following COVID-19 vaccination; the reductions in depression symptoms are similar

We find large differences based on remote work ability. Among workers not able to telework, receiving a vaccine leads to 9.8 and 5.8 percentage point reductions in anxiety and depression symptoms. For adults able to telework, we find a 7.0 percentage point reduction in anxiety symptoms that is close to statistically significant at conventional levels $(\mathrm{p}=0.07)$ and no change in depression symptoms. When looking at industry type, we do not find any change in anxiety or depression symptoms for those employed by a government or self-employed/family business. In contrast, private sector workers have a 9.2 and 8.0 percentage point reduction in anxiety and depression symptoms, respectively.

We also find similar patterns when looking at household characteristics. Among adults living in households with children, becoming vaccinated leads to a 17.3 percentage point reduction in anxiety symptoms. Among household that own their residence, becoming vaccinated leads to a 5.8 and 4.6 percentage point reduction in anxiety and depression symptoms, respectively. Households that rent have a much larger reduction, 20.9 and 18.6 percentage points, respectively.

Overall, these results highlight differential improvements in mental health outcomes following COVID-19 vaccination across different populations. These differential impacts align conceptually with the differential burdens of the COVID-19 pandemic, suggesting that populations that benefited most from COVID-19 vaccinations also experienced the largest improvements in anxiety and depression symptoms. 


\section{ROBUSTNESS TESTS}

Our primary identification assumption is that variation in vaccine eligibility increases vaccination rates but does not change mental or behavioral health symptoms through other pathways. In addition to controlling for the share of vaccinated adults and state-specific time trends, we test the validity of this assumption using two additional approaches. First, we estimate event studies that assess the reduced form association between vaccination eligibility and each mental health outcome. These event studies test for trends in anxiety/depression symptoms in the survey waves prior to an individual becoming eligible for vaccination. Because the HPS does not collect panel data, we estimate the changes in anxiety/depression symptoms for each survey respondent, relative to the time in which that individual would have been eligible for COVID-19 vaccination, given the age-based eligibility rules in their state. Our event studies thus estimate the change in outcomes relative to when a person would "aged in" to COVID-19 vaccination eligibility. As an additional test, we also estimate these event studies, but limit the post eligibility period to those who have not been vaccinated.

As shown in Figure 3, we find slightly increasing trends in regression-adjusted anxiety and depression symptoms prior to becoming eligible for vaccination. However, it is important to note that these trends are not statistically significant. Following eligibility, these trends reverse, and we find steady reductions in self-reported symptoms. By the $7^{\text {th }}$ survey wave post eligibility, we find statistically significant 6.7 and 4.7 percentage point reductions in anxiety and depression symptoms, respectively.

These reduced form event studies show reductions following eligibility, but they do not separate the improvements in mental health that come from the private benefits of vaccination vs. the external social benefits of vaccination. To disentangle these mechanisms, we estimate the 
same event studies but exclude individuals who have been vaccinated. Prior to eligibility, these populations, and thus the pre-eligibility trends, overlap. However, as shown in Figure 4, following vaccine eligibility, we observe no change in self-reported anxiety and depression symptoms among non-vaccinated individuals. Combined with the results in the rest of this paper, these null results suggest that the primary mechanism through which vaccination improves mental health occurs through private, rather than external, benefits.

\section{DISCUSSION}

The COVID-19 pandemic has had both direct health effects from COVID-19 infection and mortality, but also secondary health impacts on behavior and mental health (Breslau et al. 2021; Ettman et al. 2020). Along with the direct benefits of reducing COVID-19 infection risk, COVID-19 vaccines can also address secondary risks of the pandemic, including mental health distress (Perez-Arce et al. 2021). In this paper, we use data from a national survey collected to estimate how COVID-19 vaccination impacts anxiety and depression symptoms. After instrumenting for COVID-19 vaccination using variation in state eligibility rules, we estimate that becoming vaccinated leads to an approximately $30 \%$ reduction in mental health symptoms. Importantly, nearly all of the benefits appear to be private benefits, and we find little evidence of external mental health benefits from COVID-19 vaccination. We also find substantial heterogeneity in the impact of COVID-19 vaccination on mental health. We find larger reductions in anxiety and depression symptoms among lower-income populations, workers who lack the ability to telework, and households that rent their housing. The heterogeneity in the benefits of COVID-19 vaccinations reflects the heterogeneity in the health and economic impacts of the pandemic. 
This study is not without limitations. First, the HPS is a cross-sectional survey. Therefore, the composition of the sample frequently changes, and we are unable to estimate within-person changes in mental health or include individual-level fixed effects (Cai et al. 2021). Second, mental health outcomes are often sensitive to seasonal changes (Geoffroy et al. 2014; Heboyan, Stevens, and McCall 2019; Shapiro et al. 1990). Thus, some of the improvements we find may be due to seasonal changes. However, our fixed effects for survey panel should alleviate concerns of seasonality. Third, we focused on specific mental health outcomes that were collected in the HPS. However, there are other mental health conditions such as trauma and suicidal ideation that are not collected in the data (Park and Kim 2021). In addition, we do not examine the effect of the COVID-19 vaccines on children under the age of 18. Therefore, our results for the benefits of the COVID-19 vaccine on mental health outcomes may be an underestimate of the total effect of the rollout.

Despite these limitations, our findings point to important secondary benefits of vaccines. These secondary benefits are not commonly accounted for in most evaluations of the effectiveness of medical treatments, including vaccines. However, these secondary effects can provide large benefits to society and should be included when assessing the COVID-19 vaccine rollout. Preliminary estimates quantify that the initial rollout of the COVID-19 vaccine was associated with 140,000 deaths averted, which translates to a statistical value of life ranging from $\$ 625$ billion to $\$ 1.4$ trillion (Gupta et al. 2021). Our results show that the benefits will likely be significantly higher when including improvements in mental health. Using the Cutler and Summers (2020) estimate of $\$ 1.6$ trillion health costs of anxiety and depression during the pandemic, our results imply that with 72 percent of U.S. adults fully vaccinated (CDC 2021), the approximately $30 \%$ reduction in anxiety and depression following vaccination has an economic 
benefit of approximately $\$ 346$ billion. While COVID-19 vaccines are incredibly effective at preventing the less frequent outcome of COVID-related mortality, anxiety and depression symptoms caused by the pandemic are much more common. Thus, reducing the mental health impacts of the pandemic can lead to substantial improvements in health and well-being. 


\section{REFERENCES}

Anand, Paul, Heidi L. Allen, Robert L. Ferrer, Natalie Gold, Rolando Manuel Gonzales Martinez, Evangelos Kontopantelis, Melanie Krause, and Francis Vergunst. 2021. "Work-Related and Personal Predictors of COVID-19 Transmission: Evidence from the UK and USA." Journal of Epidemiology and Community Health, July, jech-2020215208. https://doi.org/10.1136/jech-2020-215208.

Andersson, Ola, Pol Campos-Mercade, Armando N. Meier, and Erik Wengström. 2021. "Anticipation of COVID-19 Vaccines Reduces Willingness to Socially Distance." Journal of Health Economics 80 (December): 102530. https://doi.org/10.1016/j.jhealeco.2021.102530.

Azar, Kristen M. J., Zijun Shen, Robert J. Romanelli, Stephen H. Lockhart, Kelly Smits, Sarah Robinson, Stephanie Brown, and Alice R. Pressman. 2020. "Disparities In Outcomes Among COVID-19 Patients In A Large Health Care System In California." Health Affairs 39 (7): 1253-62. https://doi.org/10.1377/hlthaff.2020.00598.

Baden, Lindsey R., Hana M. El Sahly, Brandon Essink, Karen Kotloff, Sharon Frey, Rick Novak, David Diemert, et al. 2021. "Efficacy and Safety of the MRNA-1273 SARSCoV-2 Vaccine." The New England Journal of Medicine 384 (5): 403-16. https://doi.org/10.1056/NEJMoa2035389.

Bajema, Kristina L., Rebecca M. Dahl, Mila M. Prill, Elissa Meites, Maria C. RodriguezBarradas, Vincent C. Marconi, David O. Beenhouwer, et al. 2021. "Effectiveness of COVID-19 MRNA Vaccines Against COVID-19-Associated Hospitalization - Five Veterans Affairs Medical Centers, United States, February 1-August 6, 2021." MMWR. Morbidity and Mortality Weekly Report 70 (37): 1294-99. https://doi.org/10.15585/mmwr.mm7037e3.

Baker, Marissa G. 2020. "Nonrelocatable Occupations at Increased Risk During Pandemics: United States, 2018." American Journal of Public Health 110 (8): 1126-32. https://doi.org/10.2105/AJPH.2020.305738.

Barber, Andrew, and Jeremy West. 2021. "Conditional Cash Lotteries Increase COVID-19 Vaccination Rates.” SSRN Scholarly Paper ID 3894034. Rochester, NY: Social Science Research Network. https://doi.org/10.2139/ssrn.3894034.

Blanchflower, David G., and Alex Bryson. 2021. "Biden, COVID and Mental Health in America." Working Paper 29040. Working Paper Series. National Bureau of Economic Research. https://doi.org/10.3386/w29040.

Bravata, Dena, Jonathan H. Cantor, Neeraj Sood, and Christopher M. Whaley. 2021. "Back to School: The Effect of School Visits During COVID-19 on COVID-19 Transmission." w28645. National Bureau of Economic Research. https://doi.org/10.3386/w28645.

Brehm, Margaret, Paul Brehm, and Martin Hugo Saavedra. 2021. "The Ohio Vaccine Lottery and Starting Vaccination Rates." SSRN Scholarly Paper ID 3875021. Rochester, NY: Social Science Research Network. https://doi.org/10.2139/ssrn.3875021.

Breslau, Joshua, Melissa L. Finucane, Alicia R. Locker, Matthew D. Baird, Elizabeth A. Roth, and Rebecca L. Collins. 2021. "A Longitudinal Study of Psychological Distress in the United States before and during the COVID-19 Pandemic." Preventive Medicine 143 (February): 106362. https://doi.org/10.1016/j.ypmed.2020.106362. 
Brynjolfsson, Erik, John J. Horton, Adam Ozimek, Daniel Rock, Garima Sharma, and Hong-Yi TuYe. 2020. "COVID-19 and Remote Work: An Early Look at US Data." National Bureau of Economic Research.

Cai, Christopher, Steffie Woolhandler, David U. Himmelstein, and Adam Gaffney. 2021. "Trends in Anxiety and Depression Symptoms During the COVID-19 Pandemic: Results from the US Census Bureau's Household Pulse Survey." Journal of General Internal Medicine 36 (6): 1841-43. https://doi.org/10.1007/s11606-021-06759-9.

Cajner, Tomaz, Leland D. Crane, Ryan A. Decker, John Grigsby, Adrian Hamins-Puertolas, Erik Hurst, Christopher Kurz, and Ahu Yildirmaz. 2020. "The U.S. Labor Market during the Beginning of the Pandemic Recession.” Working Paper 27159. Working Paper Series. National Bureau of Economic Research. https://doi.org/10.3386/w27159.

Carpenter, Christopher S., and Emily C. Lawler. 2019. "Direct and Spillover Effects of Middle School Vaccination Requirements.” American Economic Journal: Economic Policy 11 (1): 95-125. https://doi.org/10.1257/pol.20170067.

CDC. 2021. "COVID Data Tracker, COVID-19 Vaccinations in the United States." Centers for Disease Control and Prevention. December 21, 2021. https://covid.cdc.gov/covid-datatracker.

Centers for Disease Control and Prevention. 2020. "Healthcare Facilities: Managing Operations During the COVID-19 Pandemic." Centers for Disease Control and Prevention. 2020. https://www.cdc.gov/coronavirus/2019-ncov/hcp/guidance-hcf.html.

—. 2021. "Mental Health - Household Pulse Survey - COVID-19." October 19, 2021. https://www.cdc.gov/nchs/covid19/pulse/mental-health.htm.

Chen, Shanquan, Athina R. Aruldass, and Rudolf N. Cardinal. 2022. "Mental Health Outcomes after SARS-CoV-2 Vaccination in the United States: A National Cross-Sectional Study." Journal of Affective Disorders 298 (February): 396-99. https://doi.org/10.1016/j.jad.2021.10.134.

Czeisler, Mark É. 2020. "Mental Health, Substance Use, and Suicidal Ideation During the COVID-19 Pandemic — United States, June 24-30, 2020." MMWR. Morbidity and Mortality Weekly Report 69. https://doi.org/10.15585/mmwr.mm6932a1.

Ettman, Catherine K., Salma M. Abdalla, Gregory H. Cohen, Laura Sampson, Patrick M. Vivier, and Sandro Galea. 2020. "Prevalence of Depression Symptoms in US Adults Before and During the COVID-19 Pandemic.” JAMA Network Open 3 (9): e2019686-e2019686. https://doi.org/10.1001/jamanetworkopen.2020.19686.

Feyman, Yevgeniy, Jacob Bor, Julia Raifman, and Kevin N. Griffith. 2020. "Effectiveness of COVID-19 Shelter-in-Place Orders Varied by State.” PLOS ONE 15 (12): e0245008. https://doi.org/10.1371/journal.pone.0245008.

Geoffroy, Pierre Alexis, Frank Bellivier, Jan Scott, and Bruno Etain. 2014. "Seasonality and Bipolar Disorder: A Systematic Review, from Admission Rates to Seasonality of Symptoms." Journal of Affective Disorders 168 (October): 210-23. https://doi.org/10.1016/j.jad.2014.07.002.

Gupta, Sumedha, Jonathan Cantor, Kosali I. Simon, Ana I. Bento, Coady Wing, and Christopher M. Whaley. 2021. "Vaccinations Against COVID-19 May Have Averted Up To 140,000 Deaths In The United States." Health Affairs 40 (9): 1465-72. https://doi.org/10.1377/hlthaff.2021.00619.

Heboyan, Vahé, Scott Stevens, and William V. McCall. 2019. "Effects of Seasonality and Daylight Savings Time on Emergency Department Visits for Mental Health Disorders." 
The American Journal of Emergency Medicine 37 (8): 1476-81.

https://doi.org/10.1016/j.ajem.2018.10.056.

Jay, Jonathan, Jacob Bor, Elaine O. Nsoesie, Sarah K. Lipson, David K. Jones, Sandro Galea, and Julia Raifman. 2020. "Neighbourhood Income and Physical Distancing during the COVID-19 Pandemic in the United States.” Nature Human Behaviour, November, 1-9. https://doi.org/10.1038/s41562-020-00998-2.

Kim, Eun Ji, Lyndonna Marrast, and Joseph Conigliaro. 2020. "COVID-19: Magnifying the Effect of Health Disparities." Journal of General Internal Medicine, May, 1-2. https://doi.org/10.1007/s11606-020-05881-4.

Kleibergen, Frank, and Richard Paap. 2006. "Generalized Reduced Rank Tests Using the Singular Value Decomposition.” Journal of Econometrics 133 (1): 97-126. https://doi.org/10.1016/j.jeconom.2005.02.011.

Klompas, Michael, Madelyn Pearson, and Charles Morris. 2021. "The Case for Mandating COVID-19 Vaccines for Health Care Workers.” Annals of Internal Medicine, July. https://doi.org/10.7326/M21-2366.

Koltai, Jonathan, Julia Raifman, Jacob Bor, Martin McKee, and David Stuckler. 2021. "Does COVID-19 Vaccination Improve Mental Health? A Difference-in-Difference Analysis of the Understanding Coronavirus in America Study." MedRxiv, July, 2021.07.19.21260782. https://doi.org/10.1101/2021.07.19.21260782.

Kroenke, Kurt, Robert L. Spitzer, and Janet B. W. Williams. 2003. "The Patient Health Questionnaire-2: Validity of a Two-Item Depression Screener." Medical Care 41 (11): 1284-92. https://doi.org/10.1097/01.MLR.0000093487.78664.3C.

Lee, David S., Justin McCrary, Marcelo J. Moreira, and Jack Porter. 2020. "Valid T-Ratio Inference for IV." ArXiv:2010.05058 [Econ, q-Fin], October. http://arxiv.org/abs/2010.05058.

Li, Xiang, Christinah Mukandavire, Zulma M Cucunubá, Susy Echeverria Londono, Kaja Abbas, Hannah E Clapham, Mark Jit, et al. 2021. "Estimating the Health Impact of Vaccination against Ten Pathogens in 98 Low-Income and Middle-Income Countries from 2000 to 2030: A Modelling Study." The Lancet 397 (10272): 398-408. https://doi.org/10.1016/S0140-6736(20)32657-X.

Lim, Katherine, and Michael A. Zabek. 2021. "Women's Labor Force Exits During COVID-19: Differences by Motherhood, Race, and Ethnicity." SSRN Scholarly Paper ID 3948812. Rochester, NY: Social Science Research Network. https://doi.org/10.17016/FEDS.2021.067.

Montenovo, Laura, Xuan Jiang, Felipe Lozano Rojas, Ian M. Schmutte, Kosali I. Simon, Bruce A. Weinberg, and Coady Wing. 2020. "Determinants of Disparities in Covid-19 Job Losses.” Working Paper 27132. Working Paper Series. National Bureau of Economic Research. https://doi.org/10.3386/w27132.

Oster, Emily, Rebecca Jack, Clare Halloran, John Schoof, Diana McLeod, Haisheng Yang, Julie Roche, and Dennis Roche. 2021. "Disparities in Learning Mode Access Among K-12 Students During the COVID-19 Pandemic, by Race/Ethnicity, Geography, and Grade Level - United States, September 2020-April 2021." MMWR. Morbidity and Mortality Weekly Report 70 (26): 953-58. https://doi.org/10.15585/mmwr.mm7026e2.

Park, JungHo. 2021. "Who Is Hardest Hit by a Pandemic? Racial Disparities in COVID-19 Hardship in the U.S.” International Journal of Urban Sciences 25 (2): 149-77. https://doi.org/10.1080/12265934.2021.1877566. 
Park, JungHo, and Byoungjun Kim. 2021. "Associations of Small Business Closure and Reduced Urban Mobility with Mental Health Problems in COVID-19 Pandemic: A National Representative Sample Study." Journal of Urban Health: Bulletin of the New York Academy of Medicine 98 (1): 13-26. https://doi.org/10.1007/s11524-020-00511-0.

Perez-Arce, Francisco, Marco Angrisani, Daniel Bennett, Jill Darling, Arie Kapteyn, and Kyla Thomas. 2021. "COVID-19 Vaccines and Mental Distress.” PloS One 16 (9): e0256406. https://doi.org/10.1371/journal.pone.0256406.

Petts, Richard J., Daniel L. Carlson, and Joanna R. Pepin. 2021. "A Gendered Pandemic: Childcare, Homeschooling, and Parents' Employment during COVID-19.” Gender, Work \& Organization 28 (S2): 515-34. https://doi.org/10.1111/gwao.12614.

Plummer, Faye, Laura Manea, Dominic Trepel, and Dean McMillan. 2016. "Screening for Anxiety Disorders with the GAD-7 and GAD-2: A Systematic Review and Diagnostic Metaanalysis." General Hospital Psychiatry 39 (March): 24-31. https://doi.org/10.1016/j.genhosppsych.2015.11.005.

Polack, Fernando P., Stephen J. Thomas, Nicholas Kitchin, Judith Absalon, Alejandra Gurtman, Stephen Lockhart, John L. Perez, et al. 2020. "Safety and Efficacy of the BNT162b2 MRNA Covid-19 Vaccine." The New England Journal of Medicine 383 (27): 2603-15. https://doi.org/10.1056/NEJMoa2034577.

Polyakova, Maria, Victoria Udalova, Geoffrey Kocks, Katie Genadek, Keith Finlay, and Amy N. Finkelstein. 2021. "Racial Disparities In Excess All-Cause Mortality During The Early COVID-19 Pandemic Varied Substantially Across States." Health Affairs 40 (2): 307-16. https://doi.org/10.1377/hlthaff.2020.02142.

Raifman, Julia, Kristen Nocka, David Jones, Jacob Bor, Sarah Lipson, Jonathan Jay, Megan Cole, Noa Krawczyk, Philip Chan, and Sandro Galea. 2020. "COVID-19 US State Policy Database.” Inter-university Consortium for Political and Social Research (ICPSR). https://doi.org/10.3886/E119446V10.

Raviv, Tali, Christopher M. Warren, Jason J. Washburn, Madeleine K. Kanaley, Liga Eihentale, Hayley Jane Goldenthal, Jaclyn Russo, et al. 2021. “Caregiver Perceptions of Children's Psychological Well-Being During the COVID-19 Pandemic.” JAMA Network Open 4 (4). https://doi.org/10.1001/jamanetworkopen.2021.11103.

Roehrig, Charles. 2016. "Mental Disorders Top The List Of The Most Costly Conditions In The United States: \$201 Billion.” Health Affairs 35 (6): 1130-35. https://doi.org/10.1377/hlthaff.2015.1659.

Sadoff, Jerald, Glenda Gray, An Vandebosch, Vicky Cárdenas, Georgi Shukarev, Beatriz Grinsztejn, Paul A. Goepfert, et al. 2021. "Safety and Efficacy of Single-Dose Ad26.COV2.S Vaccine against Covid-19." The New England Journal of Medicine 384 (23): 2187-2201. https://doi.org/10.1056/NEJMoa2101544.

Shapiro, C. M., F. Blake, E. Fossey, and B. Adams. 1990. "Daylight Saving Time in Psychiatric Illness." Journal of Affective Disorders 19 (3): 177-81. https://doi.org/10.1016/01650327(90)90089-q.

Siddique, Abu Bakkar, Kingsley E. Haynes, Rajendra Kulkarni, and Meng-Hao Li. 2020. "Regional Poverty Worsens Infectious Diseases: Evidence from COVID-19 Pandemic." SSRN Scholarly Paper ID 3702682. Rochester, NY: Social Science Research Network. https://doi.org/10.2139/ssrn.3702682.

Stock, James, and Motohiro Yogo. 2005. "Testing for Weak Instruments in Linear IV Regression." In Identification and Inference for Econometric Models, edited by Donald 
W. K. Andrews, 80-108. New York: Cambridge University Press. http://www.economics.harvard.edu/faculty/stock/files/TestingWeakInstr_Stock\%2BYogo .pdf.

Thomas, Stephen J., Edson D. Moreira, Nicholas Kitchin, Judith Absalon, Alejandra Gurtman, Stephen Lockhart, John L. Perez, et al. 2021. "Safety and Efficacy of the BNT162b2 MRNA Covid-19 Vaccine through 6 Months." The New England Journal of Medicine, September. https://doi.org/10.1056/NEJMoa2110345.

Vahratian, Anjel, Stephen J. Blumberg, Emily P. Terlizzi, and Jeannine S. Schiller. 2021. "Symptoms of Anxiety or Depressive Disorder and Use of Mental Health Care Among Adults During the COVID-19 Pandemic — United States, August 2020-February 2021." Morbidity and Mortality Weekly Report 70 (13): 490-94. https://doi.org/10.15585/mmwr.mm7013e2.

Walkey, Allan J., Anica Law, and Nicholas A. Bosch. 2021. "Lottery-Based Incentive in Ohio and COVID-19 Vaccination Rates." JAMA, July. https://doi.org/10.1001/jama.2021.11048.

Whitaker, Matthew, Joshua Elliott, Marc Chadeau-Hyam, Steven Riley, Ara Darzi, Graham Cooke, Helen Ward, and Paul Elliott. 2021. "Persistent Symptoms Following SARSCoV-2 Infection in a Random Community Sample of 508,707 People." https://doi.org/10.1101/2021.06.28.21259452.

Yang, Bingyi, Angkana T. Huang, Bernardo Garcia-Carreras, William E. Hart, Andrea Staid, Matt D. T. Hitchings, Elizabeth C. Lee, et al. 2021. "Effect of Specific NonPharmaceutical Intervention Policies on SARS-CoV-2 Transmission in the Counties of the United States." Nature Communications 12 (1): 3560. https://doi.org/10.1038/s41467021-23865-8. 


\section{TABLES AND FIGURES}

Figure 1: Unadjusted trends in Depression/Anxiety Symptoms

\section{U.S. Household Pulse Survey}

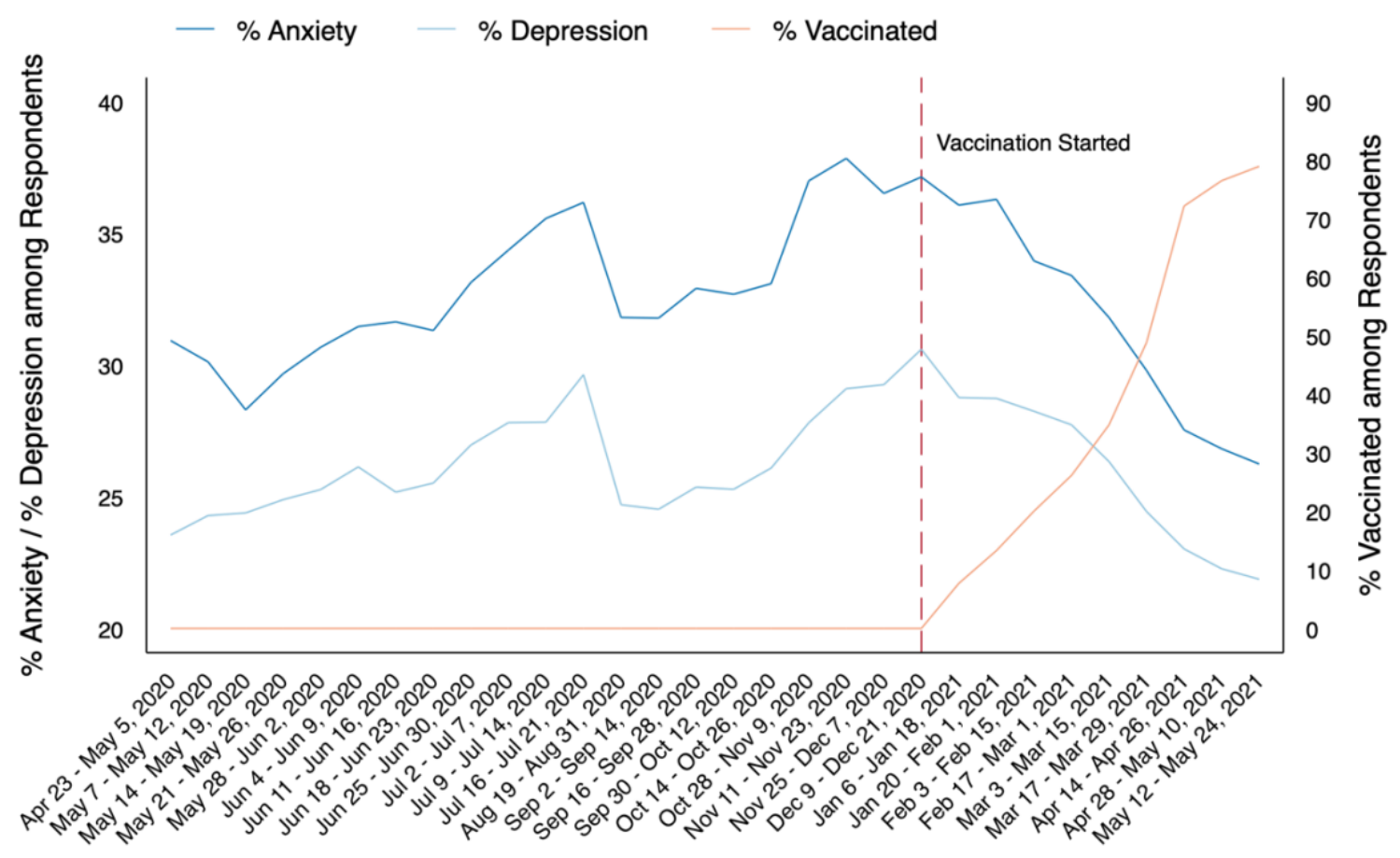

Pulse Survey Timeperiod 
Table 1: Descriptive statistics for the variables of interest $(N=2,035,847)$

\begin{tabular}{|c|c|c|c|c|}
\hline \multirow[b]{2}{*}{ Variables } & \multicolumn{2}{|c|}{ Vaccinated $(\mathrm{N}=247,406)$} & \multicolumn{2}{|c|}{ Unvaccinated $(\mathrm{N}=1,788,441)$} \\
\hline & Mean & S.D. & Mean & S.D. \\
\hline Self-reported Anxiety (\%) & $22 \%$ & $41 \%$ & $31 \%$ & $46 \%$ \\
\hline Self-reported Depression (\%) & $16 \%$ & $37 \%$ & $23 \%$ & $42 \%$ \\
\hline$\%$ Female & $59.8 \%$ & $49.0 \%$ & $59.2 \%$ & $49.1 \%$ \\
\hline \multicolumn{5}{|l|}{ Race (\%) } \\
\hline White & $81.1 \%$ & $79.6 \%$ & & \\
\hline Black & $6.0 \%$ & $7.1 \%$ & & \\
\hline Asian & $5.1 \%$ & $4.5 \%$ & & \\
\hline Hispanic & $7.8 \%$ & $8.8 \%$ & & \\
\hline \multicolumn{5}{|l|}{ Education (\%) } \\
\hline High school or less & $8.9 \%$ & & $12.9 \%$ & \\
\hline High school & $27.8 \%$ & & $31.9 \%$ & \\
\hline College & $30.5 \%$ & & $29.7 \%$ & \\
\hline Post-college & $32.7 \%$ & & $25.5 \%$ & \\
\hline \multicolumn{5}{|l|}{ Income category (\%) } \\
\hline$<\$ 35 \mathrm{k}$ & $14.7 \%$ & & $19.6 \%$ & \\
\hline$\$ 35-75 \mathrm{k}$ & $27.5 \%$ & & $28.7 \%$ & \\
\hline$\$ 75-150 \mathrm{k}$ & $35.1 \%$ & & $32.8 \%$ & \\
\hline$\$ 150 \mathrm{k}+$ & $22.7 \%$ & & $18.8 \%$ & \\
\hline \multicolumn{5}{|l|}{ Housing Status } \\
\hline Own & $81.8 \%$ & & $74.7 \%$ & \\
\hline Rent & $18.2 \%$ & & $25.3 \%$ & \\
\hline \multicolumn{5}{|l|}{ Children in Household } \\
\hline Yes & $73.1 \%$ & & $65.0 \%$ & \\
\hline No & $26.9 \%$ & & $35.0 \%$ & \\
\hline \multicolumn{5}{|l|}{ Telework Ability } \\
\hline Not able to telework & $59.3 \%$ & & $54.4 \%$ & \\
\hline Able to telework & $40.7 \%$ & & $45.7 \%$ & \\
\hline \multicolumn{5}{|l|}{ Industry } \\
\hline Government & $19.9 \%$ & & $17.6 \%$ & \\
\hline Private/non-profit & $67.0 \%$ & & $68.3 \%$ & \\
\hline Self-employed/family & $13.1 \%$ & & $14.1 \%$ & \\
\hline
\end{tabular}


Table 2: First-Stage Results of Association Between COVID-19 Vaccine Eligibility and Vaccine Receipt

\begin{tabular}{lccc}
\hline & $(1)$ & $\begin{array}{c}(2) \\
\operatorname{Pr}(\text { Received vaccine })\end{array}$ & $(3)$ \\
\hline Eligible for vaccine & & & $0.259 * * *$ \\
& $0.261^{* * *}$ & $(0.0142)$ & $0.278^{* * *}$ \\
State vaccine share & $(0.0142)$ & $0.795^{* * *}$ & $(0.0156)$ \\
& & $(0.0669)$ & \\
Observations & $2,035,847$ & $2,035,847$ & $2,035,847$ \\
R-squared & 0.562 & 0.564 & 0.566 \\
State X wave FE & & & $X$ \\
Kleibergen-Paap F-statistic & 338.5 & 334.8 & 317.6 \\
\hline
\end{tabular}

This table estimates the first-stage association between survey wave variation in the timing of COVID-19 vaccine eligibility across states and age groups on self-reported COVID-19 vaccine receipt. All regressions include controls for age, race, education, marital status, income, and gender. Column 2 controls for the share of adults vaccinated in each state-survey wave. Column 3 adds state-by-survey wave interaction fixed effects. $* * * p<0.01, * * p<0.05, * p<0.1$ 
Table 3: Effect of COVID-19 Vaccination on Anxiety and Depression Symptoms

\begin{tabular}{|c|c|c|c|c|c|c|}
\hline & $\begin{array}{c}(1) \\
\text { Anxiety }\end{array}$ & $\begin{array}{c}(2) \\
\text { Depression }\end{array}$ & $\begin{array}{c}(3) \\
\text { Anxiety }\end{array}$ & $\begin{array}{c}\text { (4) } \\
\text { Depression }\end{array}$ & $\begin{array}{c}(5) \\
\text { Anxiety }\end{array}$ & $\begin{array}{c}(6) \\
\text { Depression }\end{array}$ \\
\hline \multicolumn{7}{|l|}{ Panel A: OLS } \\
\hline Received vaccine & $\begin{array}{c}-0.0312 * * * \\
(0.00485)\end{array}$ & $\begin{array}{c}-0.0339 * * * \\
(0.00420)\end{array}$ & $\begin{array}{c}-0.0311 * * * \\
(0.00490)\end{array}$ & $\begin{array}{c}-0.0338 * * * \\
(0.00425)\end{array}$ & $\begin{array}{c}-0.0312 * * * \\
(0.00491)\end{array}$ & $\begin{array}{c}-0.0340 * * * \\
(0.00428)\end{array}$ \\
\hline State vaccine share & & & $\begin{array}{l}-0.000191 \\
(0.000382)\end{array}$ & $\begin{array}{c}-0.000174 \\
(0.000398)\end{array}$ & & \\
\hline Observations & $2,035,847$ & $2,035,847$ & $2,035,847$ & $2,035,847$ & $2,035,847$ & $2,035,847$ \\
\hline R-squared & 0.070 & 0.072 & 0.070 & 0.072 & 0.073 & 0.074 \\
\hline 2020 Mean & $32.9 \%$ & $26.3 \%$ & $32.9 \%$ & $26.3 \%$ & $32.9 \%$ & $26.3 \%$ \\
\hline Relative change & $-9.5 \%$ & $-12.9 \%$ & $-9.4 \%$ & $-12.8 \%$ & $-9.5 \%$ & $-12.9 \%$ \\
\hline State $\mathrm{X}$ wave FE & & & & & X & X \\
\hline \multicolumn{7}{|l|}{ Panel B: 2SLS } \\
\hline Received vaccine & $\begin{array}{c}-0.0944 * * * \\
(0.0141)\end{array}$ & $\begin{array}{c}-0.0723 * * * \\
(0.0123)\end{array}$ & $\begin{array}{c}-0.0948 * * * \\
(0.0141)\end{array}$ & $\begin{array}{c}-0.0725 * * * \\
(0.0123)\end{array}$ & $\begin{array}{c}-0.0917 * * * \\
(0.0152)\end{array}$ & $\begin{array}{c}-0.0713 * * * \\
(0.0115)\end{array}$ \\
\hline State vaccine share & & & $\begin{array}{c}0.000354 \\
(0.000387)\end{array}$ & $\begin{array}{c}0.000158 \\
(0.000379)\end{array}$ & & \\
\hline Observations & $2,035,847$ & $2,035,847$ & $2,035,847$ & $2,035,847$ & $2,035,847$ & $2,035,847$ \\
\hline 2020 Mean & $32.9 \%$ & $26.3 \%$ & $32.9 \%$ & $26.3 \%$ & $32.9 \%$ & $26.3 \%$ \\
\hline Relative change & $-28.7 \%$ & $-27.5 \%$ & $-28.8 \%$ & $-27.5 \%$ & $-27.8 \%$ & $-27.1 \%$ \\
\hline State $X$ wave FE & & & & & X & X \\
\hline
\end{tabular}

This table estimates the effect of COVID-19 vaccination on self-reported anxiety and depression symptoms. All regressions include controls for age, race, education, marital status, income, and gender. Columns 3 and 4 control for the share of adults vaccinated in each state-survey wave. Columns 5 and 6 add state-by-survey wave interaction fixed effects. Panel A presents OLS results and Panel B instruments for COVID-19 vaccination using state-age group variation in the timing of vaccine eligibility. $* * * \mathrm{p}<0.01, * * \mathrm{p}<0.05, * \mathrm{p}<0.1$ 
Figure 2: Heterogeneity in Effects of COVID-19 Vaccination on Anxiety and Depression Symptoms

\section{Panel A: OLS Regressions}
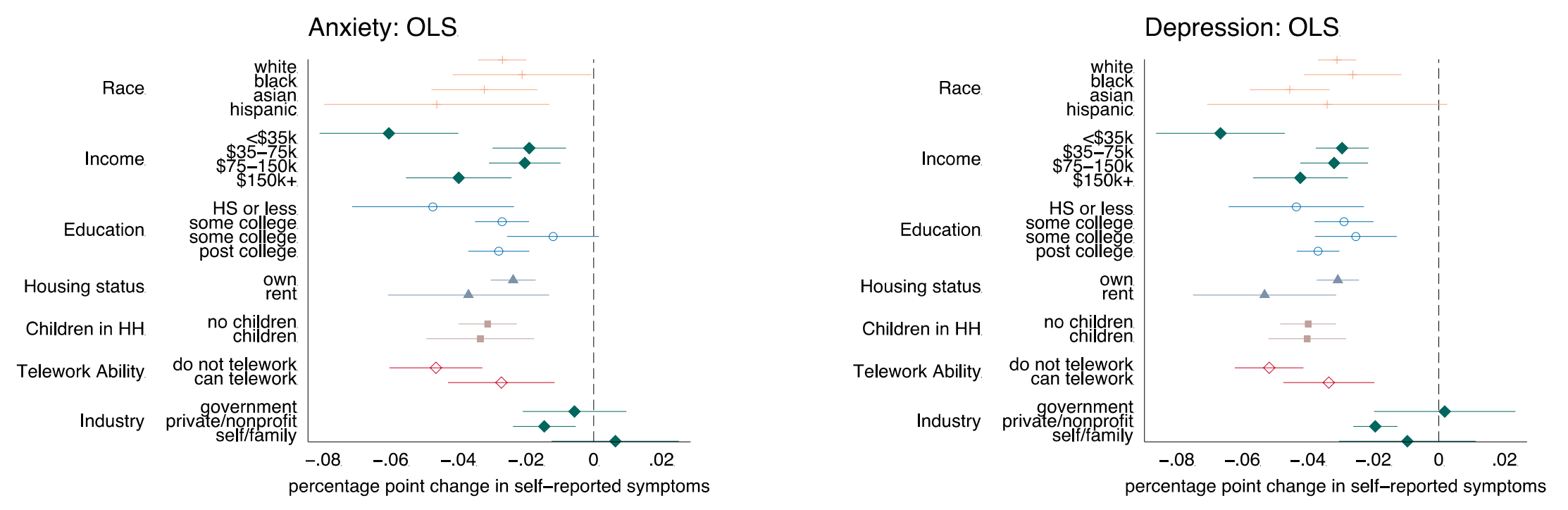

Panel B: IV Regressions
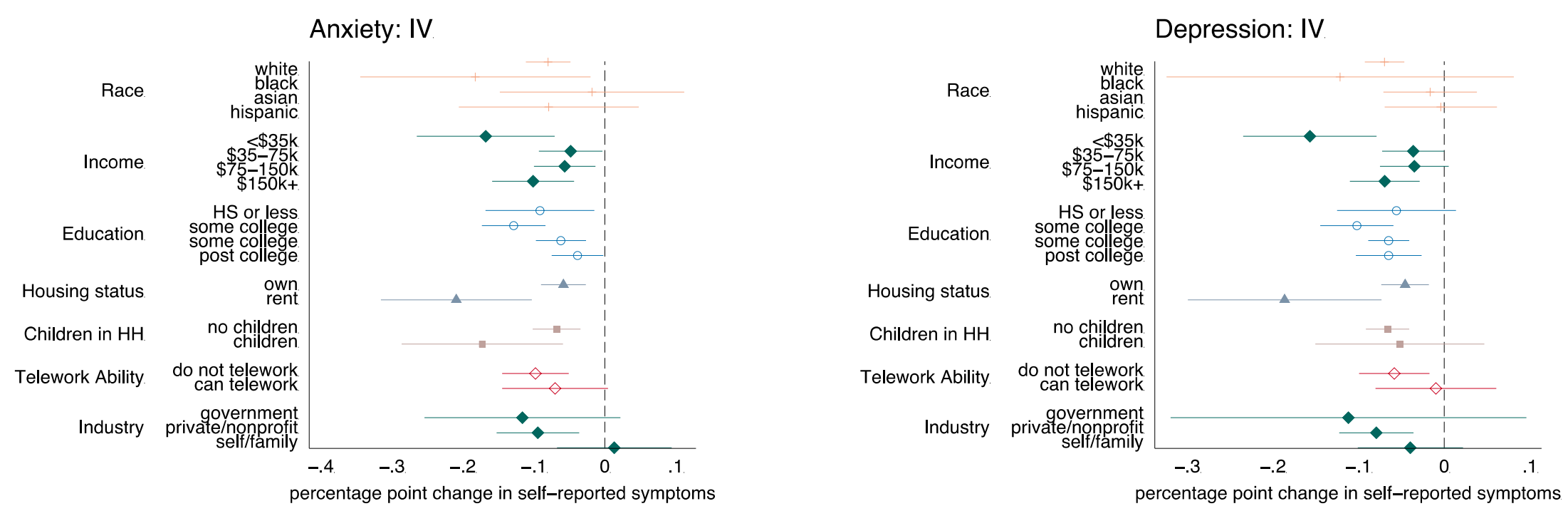
Figure 3: Event Study Results of Association Between Vaccine Eligibility and Anxiety/Depression Symptoms

\section{Panel A: Anxiety}

US - Household Pulse Survey - All Respondents

Anxiety Disorder vs Timeperiods b/w Survey Response \& Vaccine Eligibility

- Point Estimate $\quad-95 \% \mathrm{Cl}$

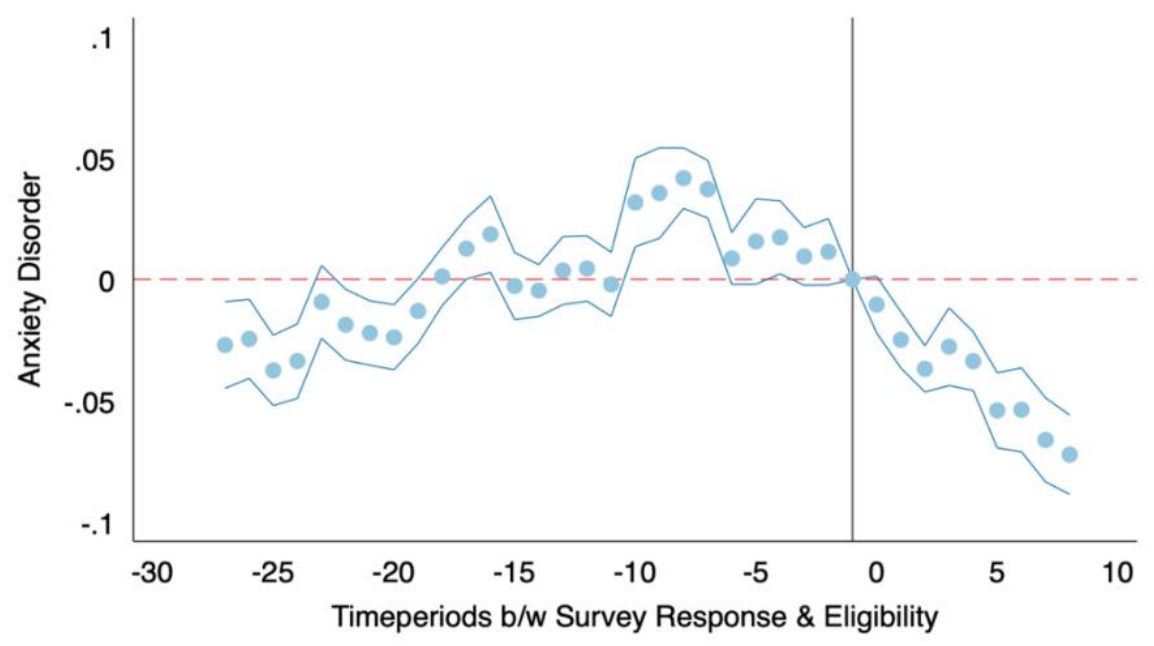

Panel B: Depression

US - Household Pulse Survey - All Respondents

Depression Disorder vs Timeperiod b/w Survey Response \& Vaccine Eligibility

- Point Estimate $\quad-95 \% \mathrm{Cl}$

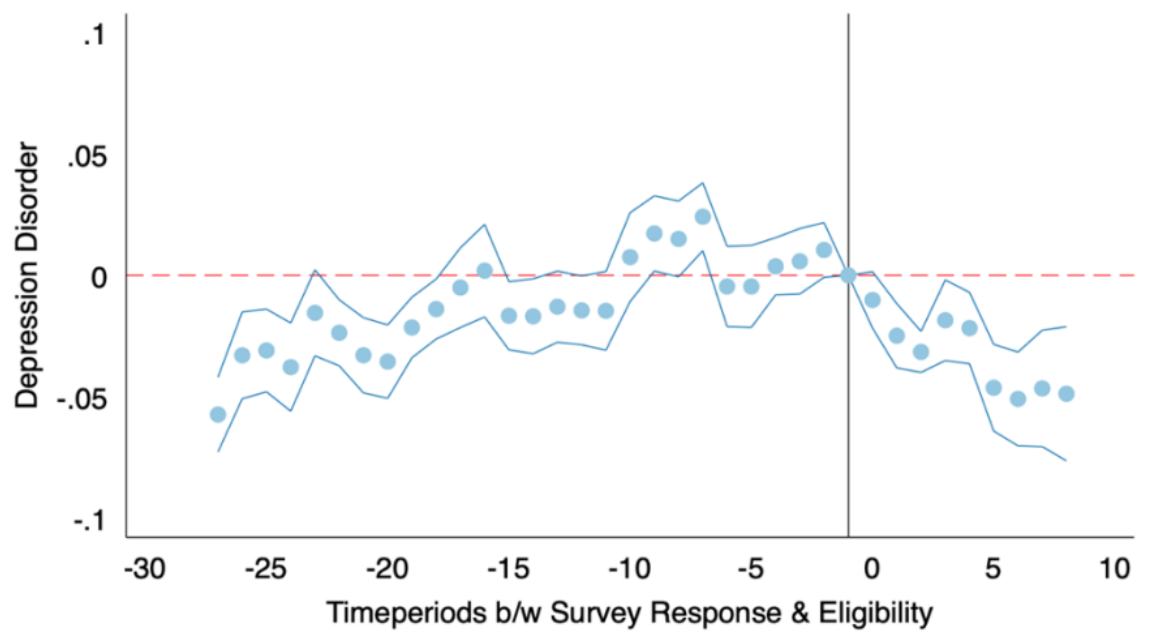


Figure 4: Event Study Results of Association Between Vaccine Eligibility and Anxiety/Depression Symptoms Among Non-Vaccinated Adults

\section{Panel A: Anxiety}

US - Household Pulse Survey - Unvaccinated Respondents

Anxiety Disorder vs Timeperiods b/w Survey Response \& Vaccine Eligibility

- Point Estimate $\quad-95 \% \mathrm{Cl}$

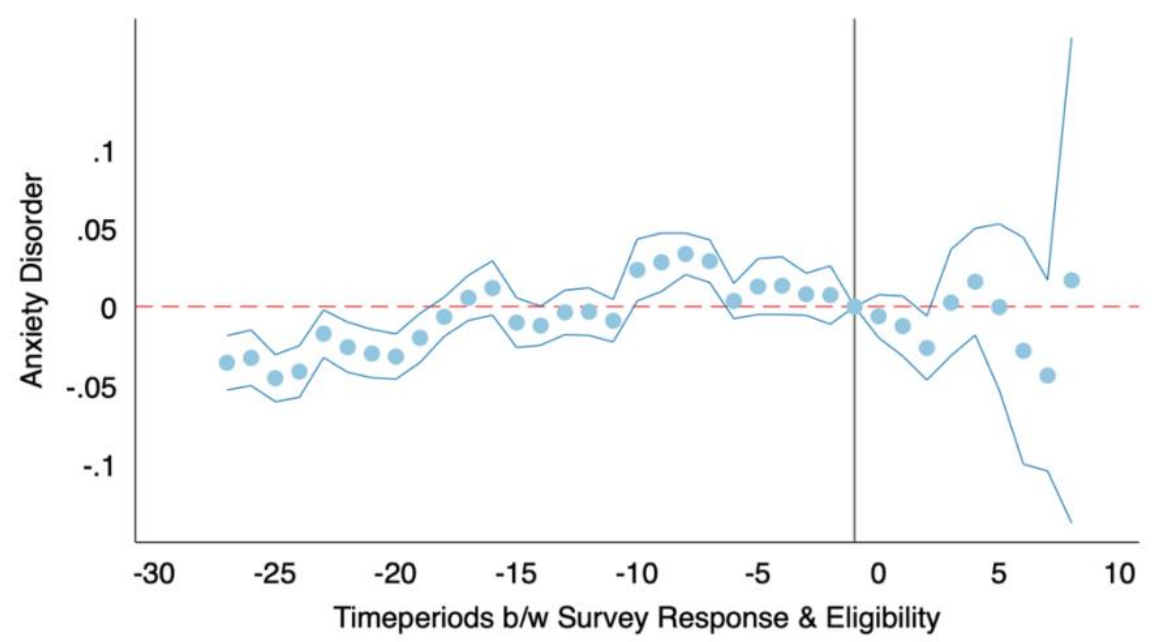

Panel B: Depression

US - Household Pulse Survey - Unvaccinated Respondents

Depression Disorder vs Weeks b/w Survey Response \& Vaccine Eligibility

- Point Estimate $\quad-95 \% \mathrm{Cl}$

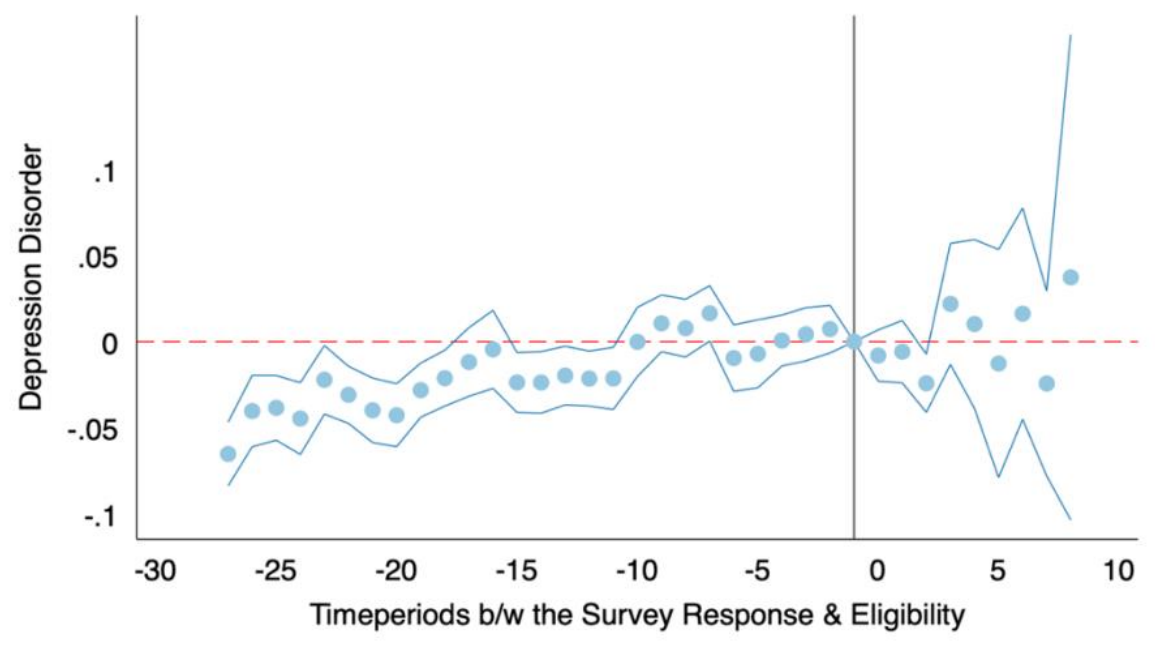




\section{APPENDIX}

\subsection{Household Pulse Survey}

The Household Pulse Survey is a nation-wide survey conducted by the U.S. Census Bureau, in collaboration with multiple federal agencies, in order to understand the impact of the COVID-19 pandemic on American households from a social and economic perspective. The sample frame of the survey is the U.S. Census Bureau Master Address File Data, and housing units linked to one or more email or phone number were randomly selected and contacted via the web. An invitation to one individual from each house unit was sent out by email and text messages. The survey has multiple phases, and each phase has multiple waves to produce statistics at three levels: national, state, and 15 metropolitan areas. We used the data from survey wave 1 to 30 for our analysis. The timeline of survey waves used in this study is listed in Table 1A below. 
Table 1A: Household Pulse Survey Waves Used in this Study

\begin{tabular}{|c|c|c|c|}
\hline Phase & Survey Wave & Start Date & End Date \\
\hline \multirow{12}{*}{1} & 1 & April 23, 2020 & May 5,2020 \\
\hline & 2 & May 7, 2020 & May 12,2020 \\
\hline & 3 & May 14,2020 & May 19,2020 \\
\hline & 4 & May 21,2020 & May 26, 2020 \\
\hline & 5 & May 28, 2020 & June 2,2020 \\
\hline & 6 & June 4,2020 & June 9,2020 \\
\hline & 7 & June 11,2020 & June 16,2020 \\
\hline & 8 & June 18,2020 & June 23,2020 \\
\hline & 9 & June 25,2020 & June 30, 2020 \\
\hline & 10 & July 2,2020 & July 7, 2020 \\
\hline & 11 & July 9,2020 & July 14,2020 \\
\hline & 12 & July 16,2020 & July 21,2020 \\
\hline \multirow{5}{*}{2} & 13 & August 19,2020 & August 31,2020 \\
\hline & 14 & September 2, 2020 & September 14,2020 \\
\hline & 15 & September 16, 2020 & September 28, 2020 \\
\hline & 16 & September 30,2020 & October 12, 2020 \\
\hline & 17 & October 14,2020 & October 26,2020 \\
\hline \multirow{10}{*}{3} & 18 & October 28,2020 & November 9, 2020 \\
\hline & 19 & November 11,2020 & November 23,2020 \\
\hline & 20 & November 25, 2020 & December 7, 2020 \\
\hline & 21 & December 9, 2020 & December 21, 2020 \\
\hline & 22 & January 6, 2021 & January 18, 2021 \\
\hline & 23 & January 20,2021 & February 1, 2021 \\
\hline & 24 & February 3,2021 & February 15,2021 \\
\hline & 25 & February 17, 2021 & March 1, 2021 \\
\hline & 26 & March 3, 2021 & March 15, 2021 \\
\hline & 27 & March 17, 2021 & March 29, 2021 \\
\hline \multirow{3}{*}{3.1} & 28 & April 14, 2021 & April 26, 2021 \\
\hline & 29 & April 28, 2021 & May 10,2021 \\
\hline & 30 & May 12, 2021 & May 24, 2021 \\
\hline
\end{tabular}

To capture the impact of the pandemic on mental wellbeing, the National Center for Health Statistics collaborated with the U.S. Census Bureau on mental health and health access measures of the survey. The four questions in the survey that focus on mental health are 1) how often have you been bothered by the following problems... Feeling nervous, anxious, or on edge?, 2) how often have you been bothered by the following problems... Not being able to stop or control worrying?, 3) how often have you been bothered by ... having little interest or pleasure in doing 
things?, and 4) how often have you been bothered by... feeling down, depressed, or hopeless? For each question, the answers are scaled from 1 to 4.1 is Not at all, 2 is Several days, 3 is More than half the days, and 4 is Nearly every day. For this study, as per the Center for Disease Control and Prevention (CDC) scoring and estimation, the index for all four questions is rescaled to 0 to 3., where 0 is Not at all, 1 is Several days, 2 is More than half the days, and 3 is Nearly every day. Following the CDC aggregation standards, the two responses on anxiety and worry, i.e., 1 and 2 are added together to create the variable "Generalized Anxiety Disorder" and the two responses on having little interest and feeling down, i.e., 3 and 4 are added together to create the variable "Major Depressive Disorder". For both Generalized Anxiety Disorder and Major Depressive Disorder, a sum equal to three or greater is associated with anxiety disorder and depressive disorder, respectively.

\subsection{Covariate Construction}

The covariates of each respondent, accessed from the HPS dataset, are discussed below.

- Age: The survey contains the birth year of each respondent. We calculated age of each respondent based on the year of the survey conducted, i.e., either 2020 or 2021.

- Gender: The survey assigned 1 for male and 2 for female.

- Hispanic: The survey assigned 1 for "Not of Hispanic origin" and 2 for "Hispanic origin." For the purpose for statistical convenience, we changed the index to 1 for "Hispanic origin" and 0 for "Not of Hispanic origin."

- Non-Hispanic Race: As per the survey, 1 is for Non-Hispanic White, 2 for NonHispanic Black, 3 for Non-Hispanic Asian and 4 for other Non-Hispanic races.

- Education: The survey indexed education from 1 to 7 , where 1 is less than high school, 2 is some high school, 3 is high school graduate or equivalent, 4 is some 
college, but degree not received or in progress, 5 is associate degree, 6 is bachelor's degree, and 7 is graduate degree. For this study we rescaled the index to $1-4$, where 1 is assigned to the original indices 1 - less than high school, 2 - some high school and 3 - high school graduate or equivalent, 2 is assigned to the original indices 4 - some college, but degree not received or in progress and 5 - associate degree, 3 is assigned to the original index 6 - bachelor's degree, and 4 is assigned to the original index 7 graduate degree.

- Marital Status: The survey indices are 1 for now married, 2 for widowed, 3 for divorced, 4 for separated, and 5 for never married. For this study we rescaled to 1-3, where 1 is never married, 2 is either widowed or divorced or separated, and 3 is never married.

- Income: The survey indices for income are as follows. 1 for less than $\$ 25,000 ; 2$ for $\$ 25,000$ to $\$ 34,999 ; 3$ for $\$ 35,000$ to $\$ 49,999 ; 4$ for $\$ 50,000$ to $\$ 74,999 ; 5$ for $\$ 75,000$ to $\$ 99,999 ; 6$ for $\$ 100,000$ to $\$ 149,999 ; 7$ for $\$ 150,000$ to $\$ 199,999$; and 8 for $\$ 200,000$ and above. For this study we rescaled to 1 from 5 , where 1 is assigned to the original indices 1 - less than $\$ 25,000,2$ - $\$ 25,000$ to $\$ 34,999$ and 3 - $\$ 35,000$ to $\$ 49,999 ; 2$ is assigned to the original indices 4 - $\$ 50,000$ to $\$ 74,999$ and 5 $\$ 75,000$ to $\$ 99,999 ; 3$ is assigned to the original index 6 - $\$ 100,000$ to $\$ 149,999 ; 4$ is assigned to the original index 7 - $\$ 150,000$ to $\$ 199,999$; and 5 is assigned to the original index 8 - $\$ 200,000$ and above. 